\title{
Neuroprotection by leptin in a rat model of permanent cerebral ischemia: effects on STAT3 phosphorylation in discrete cells of the brain
}

\author{
D Amantea ${ }^{\star, 1}$, C Tassorelli ${ }^{2}$, R Russo ${ }^{1}$, F Petrelli ${ }^{1}$, LA Morrone ${ }^{1}$, G Bagetta ${ }^{1}$ and MT Corasaniti ${ }^{3}$
}

In addition to its effects in the hypothalamus to control body weight, leptin is involved in the regulation of neuronal function, development and survival. Recent findings have highlighted the neuroprotective effects of leptin against ischemic brain injury; however, to date, little is known about the role performed by the signal transducer and activator of transcription (STAT)-3, a major mediator of leptin receptor transduction pathway in the brain, in the beneficial effects of the hormone. Our data demonstrate that systemic acute administration of leptin produces neuroprotection in rats subjected to permanent middle cerebral artery occlusion (MCAo), as revealed by a significant reduction of the brain infarct volume and neurological deficit up to 7 days after the induction of ischemia. By combining a subcellular fractionation approach with immunohistofluorescence, we observe that neuroprotection is associated with a cell type-specific modulation of STAT3 phosphorylation in the ischemic cortex. The early enhancement of nuclear phospho-STAT3 induced by leptin in the astrocytes of the ischemic penumbra may contribute to a beneficial effect of these cells on the evolution of tissue damage. In addition, the elevation of phospho-STAT3 induced by leptin in the neurons after $24 \mathrm{~h} \mathrm{MCAO}$ is associated with an increased expression of tissue inhibitor of matrix metalloproteinases-1 in the cortex, suggesting its possible involvement to the neuroprotection produced by the adipokine.

Cell Death and Disease (2011) 2, e238; doi:10.1038/cddis.2011.125; published online 8 December 2011

Subject Category: Neuroscience

Leptin is a $16-\mathrm{kDa}$ protein hormone, secreted primarily by the white adipose tissue in direct proportion to body fat stores, which functions in the hypothalamus to regulate the body weight by reducing food intake and by increasing energy expenditure. Leptin exerts multiple effects on the reproduction, neuroendocrine system, immune reactions, and recent studies implicate this protein in the regulation of neuronal function, ${ }^{1}$ development ${ }^{2}$ and survival. ${ }^{3}$

Leptin receptors (ObRs) originate from alternative splicing of a single mRNA and are classified as the short (ObRa, c, d, f), long (ObRb) and soluble (ObRe) forms. The long isoform is abundantly expressed in the hypothalamus and is thought to mediate many of the physiological actions of leptin, in particular those controlling feeding and energy balance; whereas the short form appears to mediate the transfer of leptin from the periphery through the blood brain barrier. ${ }^{4}$ ObRs have also been found in several other regions of the mammalian brain, being expressed both in the neurons and in glial cells. ${ }^{5-7}$

ObR is a member of the class I cytokine receptor superfamily. ${ }^{8}$ Upon leptin binding, ObR activates the Janus tyrosine kinase (JAK)-2, which in turn recruits signal transducer and activator of transcription (STAT)-3 proteins to the receptor. Upon phosphorylation, STAT3 dimerizes and translocates to the nucleus where it regulates the expression of target genes. ${ }^{9}$ Alternative downstream targets of leptin signaling include extracellular signal-regulated kinase (ERK) 1/2 and phosphatidylinositol 3-kinase (PI3K), which subsequently activates the prosurvival factor protein kinase B/Akt. These signaling pathways underlie the neurotrophic and neuroprotective roles of leptin. ${ }^{3}$

Recent findings have highlighted the neuroprotective effects of leptin against ischemic injury both in vitro and in vivo. ${ }^{5,10}$ Although various mechanisms, including the activation of ERK1/2, Akt and c-Rel, have been suggested to underlie the beneficial effects of the hormone, little is known about the role of STAT3, a major mediator of ObR transduction pathway in the brain. ${ }^{9}$ Thus, in order to unravel the role of this mediator in leptin-induced neuroprotection in stroke, here, we provide a comprehensive evaluation of STAT3 activation by combining a subcellular fractionation approach with immunohistofluorescence. Our data demonstrate that leptin

\footnotetext{
${ }^{1}$ Department of Pharmacobiology and University Consortium for the Study of Adaptive Disorders and Head Pain, Section of Neuropharmacology of Normal and Pathological Neuronal Plasticity, University of Calabria, Rende (CS), Italy; ${ }^{2}$ IRCCS 'National Neurological Institute C Mondino' Foundation and University Consortium for the Study of Adaptive Disorders and Head Pain, University of Pavia, Pavia, Italy and '3epartment of Health Sciences, University 'Magna Graecia' of Catanzaro, Catanzaro, Italy

${ }^{*}$ Corresponding author: D Amantea, Department of Pharmacobiology, University of Calabria, via P. Bucci, Ed. Polifunzionale, 87036, Rende (CS), Italy. Tel: + 390984 493189; Fax: + 390984 493270; E-mail: amantea@unical.it

Keywords: astrocytes; leptin; neuroinflammation; STAT3; stroke

Abbreviations: ERK, extracellular signal-regulated kinase; GFAP, glial fibrillary acidic protein; JAK, Janus tyrosine kinase; MCAo, middle cerebral artery occlusion; NeuN, neuronal nuclei; ObR, leptin receptor; OGD, oxygen-glucose deprivation; p-Akt, phospho-Akt; PBS, phosphate-buffered saline; PI3K, phosphatidylinositol 3-kinase; p-STAT3, phospho-STAT3; STAT-3, signal transducer and activator of transcription-3; TIMP-1, tissue inhibitor of matrix metalloproteinases-1; TTC, triphenyltetrazolium chloride

Received 17.10.11; accepted 26.10.11; Edited by G Melino
} 
exerts a significant reduction of the brain infarct damage and neurological deficit induced by permanent focal cerebral ischemia in the rat, and this is associated with a cell type-specific modulation of STAT3 phosphorylation in the ischemic cortex.

\section{Results}

Systemic administration of leptin significantly reduced the brain infarct damage produced by $24 \mathrm{~h}$ permanent middle cerebral artery occlusion (MCAo) in the rat. Neuroprotection was observed when leptin was administered subcutaneously (s.c.) at the dose of $1 \mathrm{mg} / \mathrm{kg}, 3 \mathrm{~h}$ before MCAo (Figure 1a). By contrast, the same dose of leptin administered $6 \mathrm{~h}$ or immediately before the induction of ischemia produced only a slight, not statistically significant, reduction of infarct volume as compared with vehicle-treated animals (Figure 1a). Administration of a lower dose of leptin $(0.1 \mathrm{mg} / \mathrm{kg}, 3 \mathrm{~h}$ before MCAo) resulted in an infarct volume (534.9 \pm $56 \mathrm{~mm}^{3}, n=3$ ) comparable to that observed in vehicleinjected (phosphate-buffered saline (PBS), $1 \mathrm{ml} / \mathrm{kg}$ s.c.) animals $\left(508.1 \pm 35.9 \mathrm{~mm}^{3}, n=5\right)$.

Brain damage produced by MCAo in the animals treated with vehicle (PBS, $1 \mathrm{ml} / \mathrm{kg}$ s.c.) involved the brain regions supplied by the middle cerebral artery, including the striatum and the frontoparietal cortex (Figure 1b). Administration of leptin ( $1 \mathrm{mg} / \mathrm{kg}$, s.c., $3 \mathrm{~h}$ before MCAo) significantly reduced ischemic brain damage in perifocal regions such as the medial caudate-putamen and the motor cortex (Figures $1 \mathrm{~b}$ and $\mathrm{c}$ ). To exclude the possibility that neuroprotection by leptin was due to altered cerebral blood perfusion, we have monitored regional cerebral blood flow (CBF) and found no difference between vehicle- and leptin-treated animals. Reduction of cortical CBF, as monitored for $10 \mathrm{~min}$ after the induction of MCAo was $21 \pm 3 \%$ of basal in vehicle-injected animals and $18 \pm 3 \%$ of basal in rats treated with leptin.

To determine whether neuroprotection by leptin persists over time, we have measured the brain infarct volume and neurological deficit up to 7 days after MCAo. A significant reduction of the brain infarct volume was observed in rats treated with leptin ( $1 \mathrm{mg} / \mathrm{kg}$, s.c., $3 \mathrm{~h}$ before MCAo) as determined either 3 or 7 days after permanent ischemia (Figure 2a). Neuroprotection was accompanied by a significant reduction of neurological deficit 3, 4 and 7 days after ischemia, as compared with vehicle-treated rats (Figure $2 b$ ); whereas the reduction of body weight was not affected by leptin treatment (Figure 2c).

Western blotting analysis of phosphorylated STAT3 expression in cortical brain tissue homogenates shows that phospho-STAT3 (p-STAT3) immunoreactivity is faintly detectable in the cerebral cortex after sham operation (Figure 3). Faint immunoreactivity for p-STAT3 was also detected in the contralateral, non-ischemic, cerebral cortex whereas it significantly $(P<0.001)$ increased in the ipsilateral, ischemic cortex of rats subjected to $3 \mathrm{~h}$ MCAo (Figure 3). After $24 \mathrm{~h}$ ischemia, STAT3 phosphorylation further increased in the ipsilateral cortex along with enhanced immunoreactivity also occurring in the contralateral cortex. STAT3 phosphorylation was not affected by leptin treatment $3 \mathrm{~h}$ after MCAO; however, levels of p-STAT3 in the ischemic cortex tended to be higher in leptin-treated rats $24 \mathrm{~h}$ after permanent ischemia and statistically significant $(P<0.05)$ differences between contralateral and ipsilateral p-STAT3 were, indeed, observed only in rats treated with leptin (Figure 3).

Western blotting analysis of phosphorylated Akt documented quite similar levels of phospho-Akt ( $p$-Akt) immunoreactivity in cortical homogenates from contralateral side and sham-operated animals (Figure 3). Ischemic insult increased levels of Akt phosphorylation in the cortex $3 \mathrm{~h}$ after MCAo (Figure 3). Akt phosphorylation in the ischemic cortex was not affected by leptin treatment $3 \mathrm{~h}$ after MCAo; however, a statistically significant $(P<0.05)$ increase of Akt phosphorylation versus ipsilateral cortex of sham-operated rats was observed only in leptin-treated animals (Figure 3 ). In contrast to STAT3 phosphorylation, levels of $p$-Akt no further increased $24 \mathrm{~h}$ after MCAo; indeed, they were lower than a

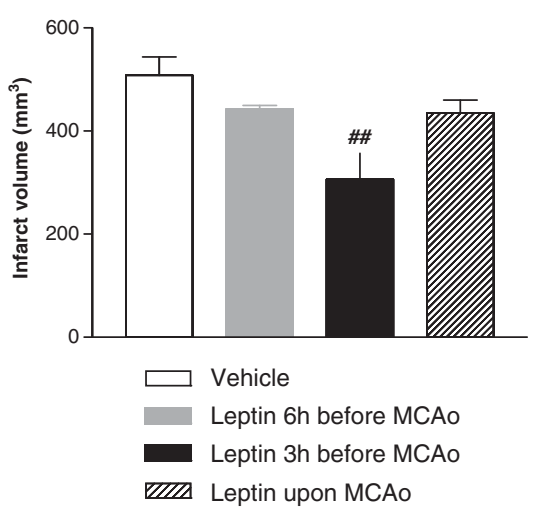

b Vehicle

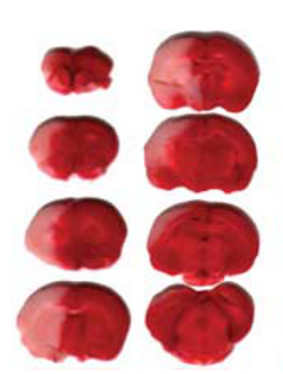

Leptin

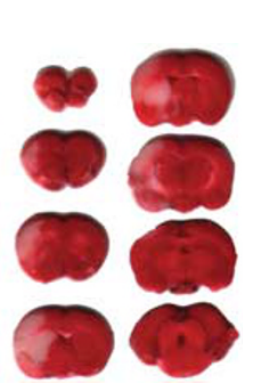

C

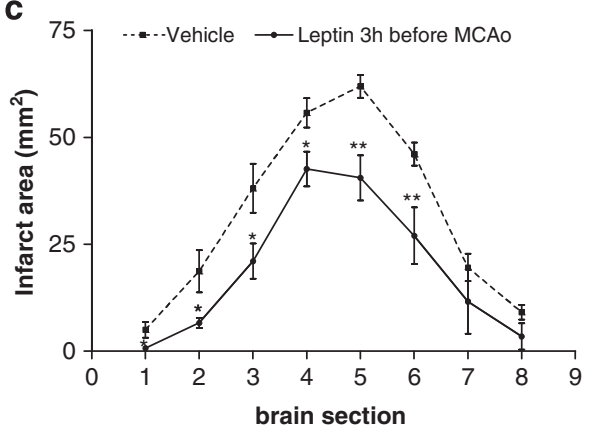

Figure 1 Systemic (s.c.) administration of leptin at the dose of $1 \mathrm{mg} / \mathrm{kg}, 3 \mathrm{~h}$ before the induction of ischemia, significantly reduces the brain infarct volume produced by $24 \mathrm{~h}$ permanent MCAO. By contrast, the same dose of leptin, administered $6 \mathrm{~h}$ or immediately before MCAo produces values of infarct volume comparable to those observed in vehicle-treated animals (a). ${ }^{\# \#} P<0.01$ versus vehicle (one-way ANOVA followed by Dunnett's post-hoc test; $n=5-6$ rats per experimental group). (b) Representative TTCstained brain slices and (c) corresponding values of infarct areas from rats subjected to $24 \mathrm{~h}$ permanent MCAo and treated (s.c.) with vehicle (PBS, $1 \mathrm{ml} / \mathrm{kg}$ ) or leptin (1 mg/kg) $3 \mathrm{~h}$ before the induction of ischemia. Ischemic brain damage (pale area) involves the brain regions supplied by the middle cerebral artery, including the striatum and the cortex. Administration of leptin reduces ischemic brain damage in perifocal regions such as the medial caudate-putamen and the motor cortex. ${ }^{*} P<0.05$ and ${ }^{* *} P<0.01$ versus corresponding brain section of vehicle-treated animals (Student's $t$ test, $n=6$ rats per experimental group) 

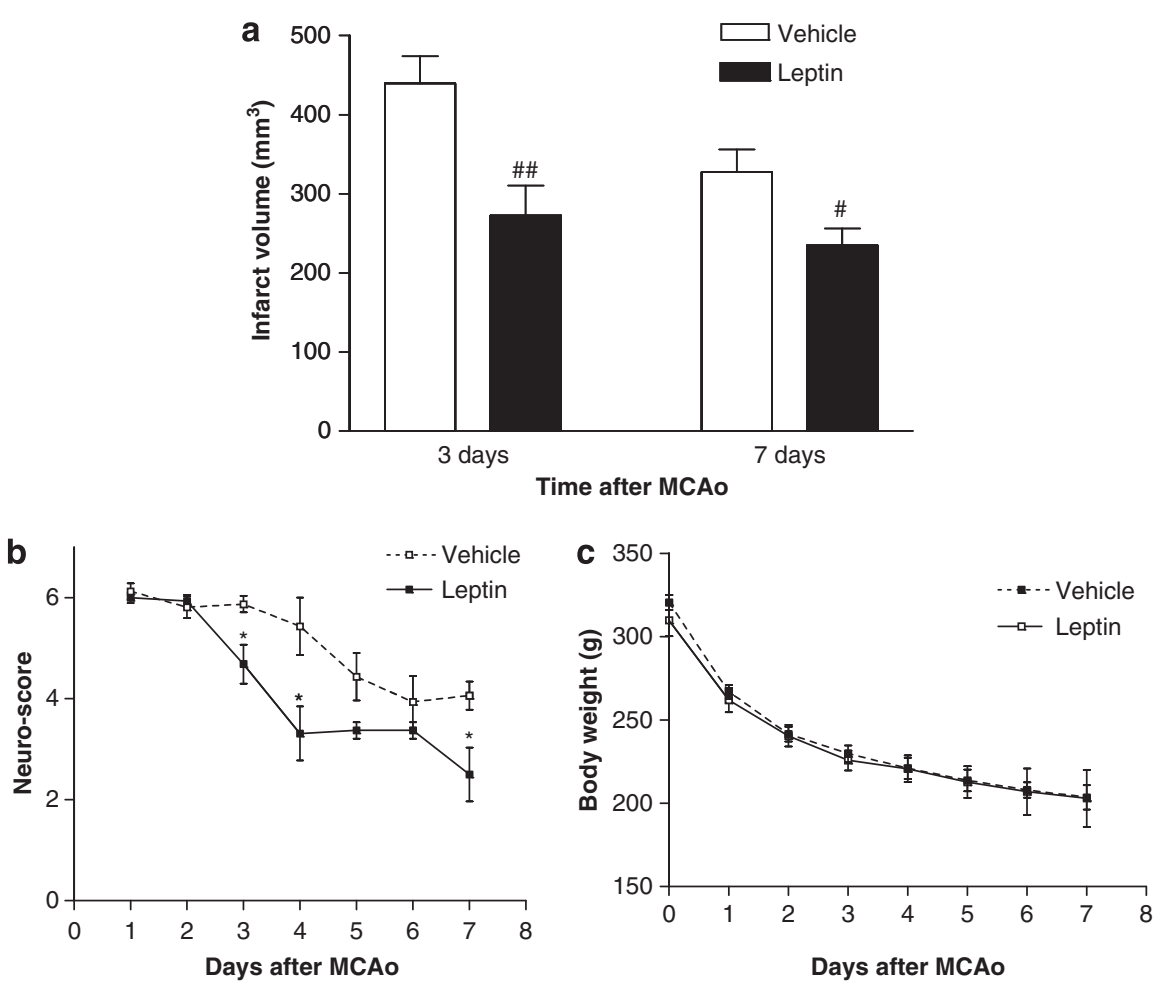

Figure 2 (a) Brain infarct volume assessed 3 and 7 days after permanent MCAo in rats treated (s.c.) with vehicle (PBS, $1 \mathrm{ml} / \mathrm{kg}$ ) or leptin $(1 \mathrm{mg} / \mathrm{kg}) 3 \mathrm{~h} \mathrm{before} \mathrm{the} \mathrm{induction}$ of ischemia. ${ }^{\#} P<0.05$ and ${ }^{\# \#} P<0.01$ versus corresponding brain section of vehicle-treated animals (Student's $t$ test, $n=4-6$ rats per experimental group). (b) Neuroscore and (c) body weight measured for 7 consecutive days after permanent MCAo in rats treated (s.c.) with vehicle (PBS, $1 \mathrm{ml} / \mathrm{kg}$ ) or leptin (1 mg/kg) $3 \mathrm{~h}$ before the induction of ischemia. ${ }^{*} P<0.05$ versus corresponding score in vehicle-injected animals (Student's $t$ test, $n=4$ rats per experimental group)
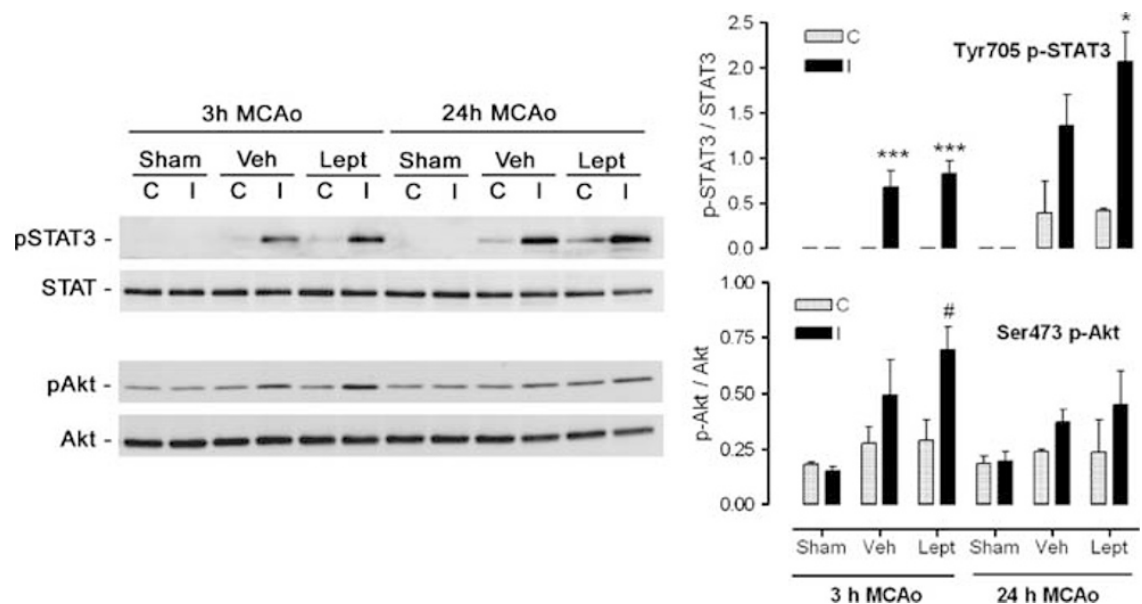

Figure 3 Changes in STAT3 and Akt phosphorylation following focal cerebral ischemia as determined by western blot analysis of phospho-STAT3 (Tyr705; p-STAT3), total STAT3, p-Akt (Ser473; p-Akt) and total Akt performed on brain cortical homogenates from the ipsilateral (I) and contralateral (C) cortex of rats treated with vehicle (Veh) or leptin (Lept) and killed 3 or $24 \mathrm{~h}$ after MCAo. The results are representative of three independent experiments. Histograms show the results of the densitometric analysis of the autoradiographic bands; ${ }^{*} P<0.05$ and ${ }^{\star \star \star} P<0.001$ versus contralateral $(C)$ side. ${ }^{\#} P<0.05$ versus Sham $3 \mathrm{~h}$

those observed at $3 \mathrm{~h}$ in both the vehicle and leptin groups (Figure 3). Thus, Akt phosphorylation transiently increases following ischemic brain insult whereas STAT3 phosphorylation progressively increases up to $24 \mathrm{~h}$; further, $\mathrm{p}$-STAT3 immunoreactivity at $24 \mathrm{~h}$ after MCAo is enhanced also in the contralateral brain cortex (Figure 3). Leptin does not affect the time course of STAT3 and Akt phosphorylation induced by ischemia but it selectively enhances Akt phosphorylation $3 \mathrm{~h}$ after MCAo and STAT3 phosphorylation $24 \mathrm{~h}$ after ischemia (Figure 3).

Upon tyrosine phosphorylation triggered by diverse stimuli, including growth factors, cytokines and hormones, STAT3 dimerizes and translocates to the nucleus to induce gene transcription. ${ }^{11}$ Therefore, under the present experimental conditions, we determined whether or not neuroprotection afforded by leptin was associated with changes of nuclear 
p-STAT3 levels in the brain cortex from rats subjected to permanent focal ischemia.

Phosphorylated STAT3 was faintly detectable in the nuclear and cytosolic fractions from contralateral cerebral cortex after $3 \mathrm{~h}$ MCAo. Interestingly, immunoreactivity for p-STAT3 was enhanced in the nuclear, but not in the cytosolic, fraction from the contralateral cortex $24 \mathrm{~h}$ after occlusion (Figure 4). Ischemic insult significantly increased levels of STAT3 phosphorylation in both the cytosolic and nuclear fractions of the ipsilateral, ischemic brain cortex $3 \mathrm{~h}$ after MCAo $(P<0.05$ versus contralateral) and these further increased in the nuclear $(P<0.001$ versus $3 \mathrm{~h})$ but not in the cytosolic fraction of ischemic cortex $24 \mathrm{~h}$ after occlusion. A similar trend was observed in rats pretreated with leptin (Figure 4); however, in comparison with vehicle-treated animals, leptin further increased STAT3 phosphorylation in the nuclear fraction $(P<0.01) 3 \mathrm{~h}$ after MCAo and in the cytosolic fraction $(P<0.01) 24 \mathrm{~h}$ after ischemia (Figure 4$)$.

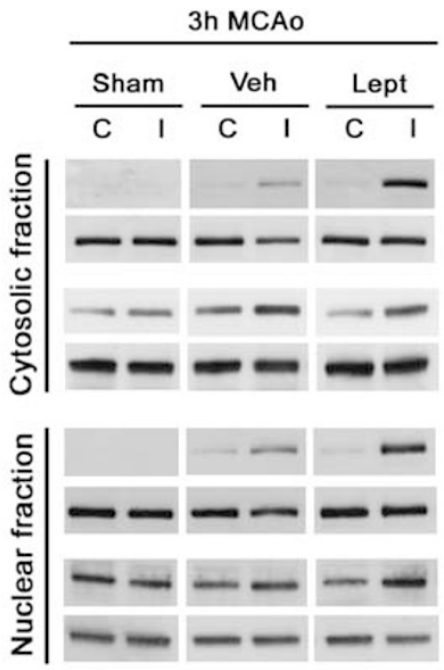

$\frac{24 h \text { MCAo }}{\frac{\text { Sham }}{\text { C I I C I }} \frac{\text { Veh }}{\text { Lept I }}}$
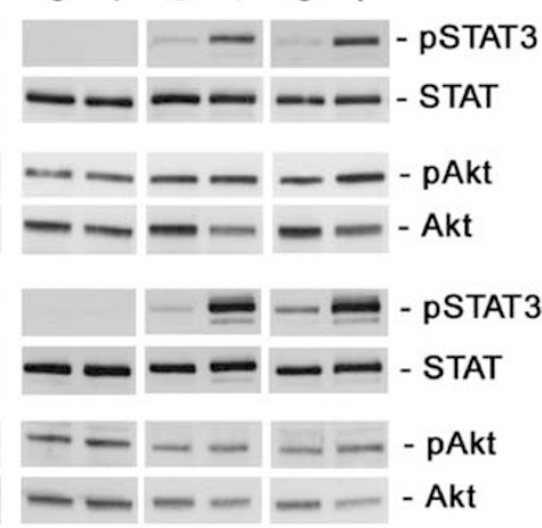

Cytosolic fraction
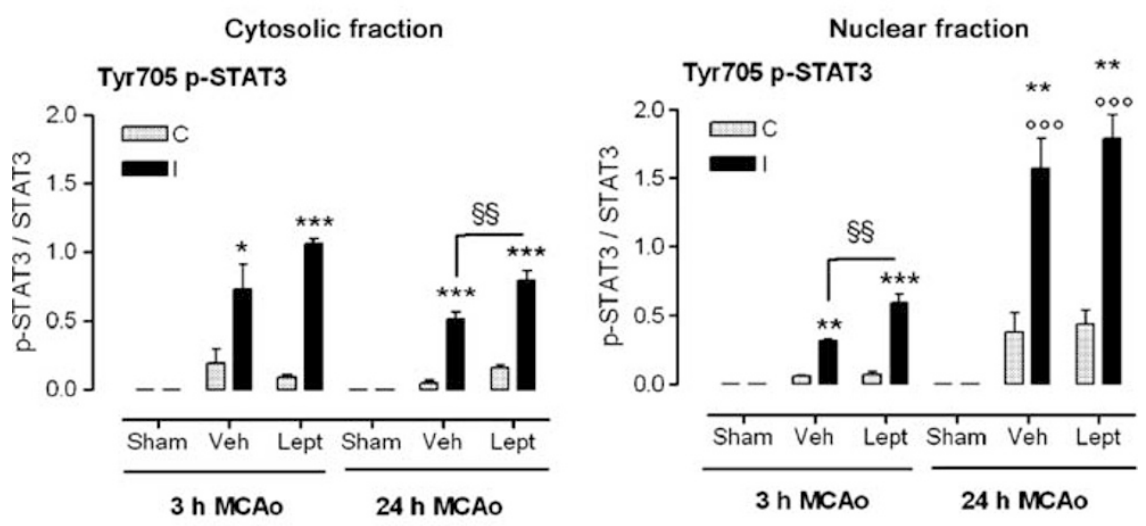

Ser473 p-Akt

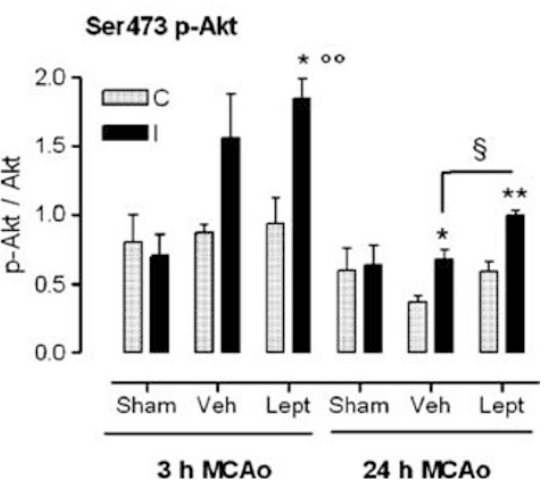

Figure 4 Changes in STAT3 and Akt phosphorylation following focal cerebral ischemia as determined by western blot analysis of phospho-STAT3 (Tyr705; p-STAT3) total STAT3, p-Akt (Ser473; p-Akt) and total Akt performed on the cytosolic and nuclear fractions of brain cortical homogenates from the ipsilateral (I) and contralateral (C) cortex of rats treated with vehicle (Veh) or leptin (Lept) and killed 3 or $24 \mathrm{~h}$ after MCAo. The results are representative of three independent experiments. Histograms show the results of the densitometric analysis of the autoradiographic bands; ${ }^{*} P<0.05,{ }^{* \star} P<0.01$ and ${ }^{\star \star \star} P<0.001$ versus contralateral (C) side. ${ }^{\S} P<0.05$ and ${ }^{\S \S} P<0.01$ (Leptin versus Vehicle). ${ }^{\circ} \mathrm{P}<0.05,{ }^{\circ 0} \mathrm{P}<0.01$ and ${ }^{\circ 00} \mathrm{P}<0.001$ (3h versus $24 \mathrm{~h}$ ) 
p-Akt immunoreactivity was detected in the cytosolic and nuclear fractions from contralateral side and sham-operated animals brain cortex at both 3 and $24 \mathrm{~h}$ after MCAo (Figure 4). Akt phosphorylation enhanced in both the cytosolic and nuclear fractions from the ischemic cortex $3 \mathrm{~h}$ after ischemia but it no further increased after $24 \mathrm{~h}$ (Figure 4); nonetheless, compared with the contralateral cortex, higher levels $(P<0.05)$ of Akt phosphorylation were reported in the nuclear fraction from the ischemic cortex $24 \mathrm{~h}$ after MCAo (Figure 4). Leptin does not affect the time course of Akt phosphorylation induced by ischemia but it significantly $(P<0.05)$ enhanced
Akt phosphorylation in the nuclear fraction $24 \mathrm{~h}$ after ischemia (Figure 4).

Immunofluorescence analysis of p-STAT3 expression confirmed that this mediator is barely detectable in shamoperated animals (data not shown); whereas it significantly increases in the brain of rats subjected to permanent MCAo with a different regional and cellular pattern depending on the stage of the insult. In fact, after $3 \mathrm{~h}$ permanent MCAo, p-STAT3 immunoreactivity was significantly increased in the peri-infarct regions of the ipsilateral hemisphere, namely the ventral striatum and the motor cortex (Figure 5e) as compared
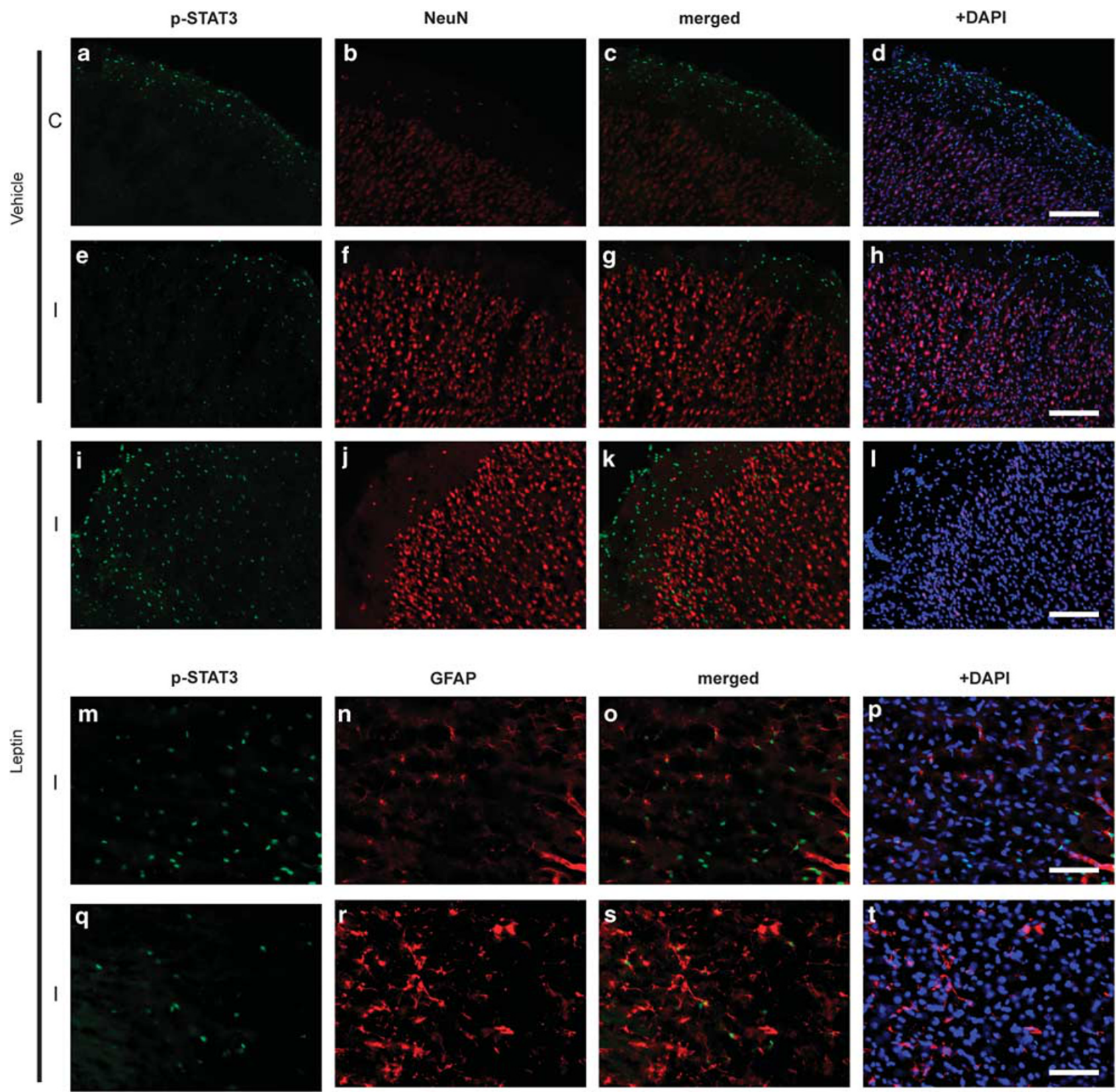

Figure 5 Double p-STAT3/NeuN $(\mathbf{a}-\mathbf{l})$ and p-STAT3/GFAP $(\mathbf{m}-\mathbf{t})$ immunoreactivity in the contralateral $(\mathbf{C})$ and ipsilateral $(\mathbf{l})$ motor $(\mathbf{a}-\mathbf{p})$ and frontal $(\mathbf{q}-\mathbf{t})$ cortices of rats subjected to $3 \mathrm{~h}$ permanent MCAo. Leptin (1 mg/kg, s.c.) or vehicle (PBS, $1 \mathrm{ml} / \mathrm{kg}$ ) were administered $3 \mathrm{~h}$ before the induction of ischemia. Phospho-STAT3 expression in the contralateral hemisphere of leptin-treated rats was not significantly different from the contralateral hemisphere of vehicle-injected animals shown in panel (a). Nuclei were counterstained with 4',6-diamidino-2-phenylindole (DAPI). Scale bars $=200 \mu \mathrm{m}(\mathbf{a}-\mathrm{I})$ and $100 \mu \mathrm{m}(\mathbf{m}-\mathbf{t})$ 
with the contralateral hemisphere (Figure 5a). Moreover, at this stage of the insult, p-STAT3 immunoreactivity was also detected in the meninges and in the periventricular areas of the ipsilateral hemisphere, and in the external layer of the contralateral motor cortex (Figures $5 \mathrm{a}-\mathrm{d}$ ). In the core region of the striatum, p-STAT3 was only detected in intravascular cells (data not shown). In the cortex, p-STAT3 increased in nonneuronal cells, as shown by the lack of merging with the NeuN neuronal marker (Figures 5c, g and k), most of which appear to be astrocytes as demonstrated by the colocalization with the astrocytic marker glial fibrillary acidic protein (GFAP; Figures 50 and s). Interestingly, pretreatment with leptin (1 mg/kg, s.c., $3 \mathrm{~h}$ before MCAo) significantly increased p-STAT3 expression in the cortical penumbra
(Figures $5 \mathrm{i}$ versus e), and, in particular, in the nuclei of astrocytes localized in the motor cortex (Figure 50) and in the internal layers of the frontal cortex (Figure $5 \mathrm{~s}$ ).

An increase of p-STAT3 immunoreactivity after leptin pretreatment was also observed in the cortex of rats subjected to $24 \mathrm{~h}$ permanent MCAo (Figure 6). At this stage of the insult, the expression of p-STAT3 was mainly observed in the neurons and other (probably microglial) cells of the peri-infarct region of the motor cortex (Figures 6a-h); whereas, in the core region of the parietal cortex, p-STAT3 was only expressed in non-neuronal (probably microglial) cells (Figures $6 m-p$ ). By contrast, in the internal layer of the frontal cortex, a clear co-localisation of $p$-STAT3 with the astrocytic marker GFAP was observed (Figures 6q-t).
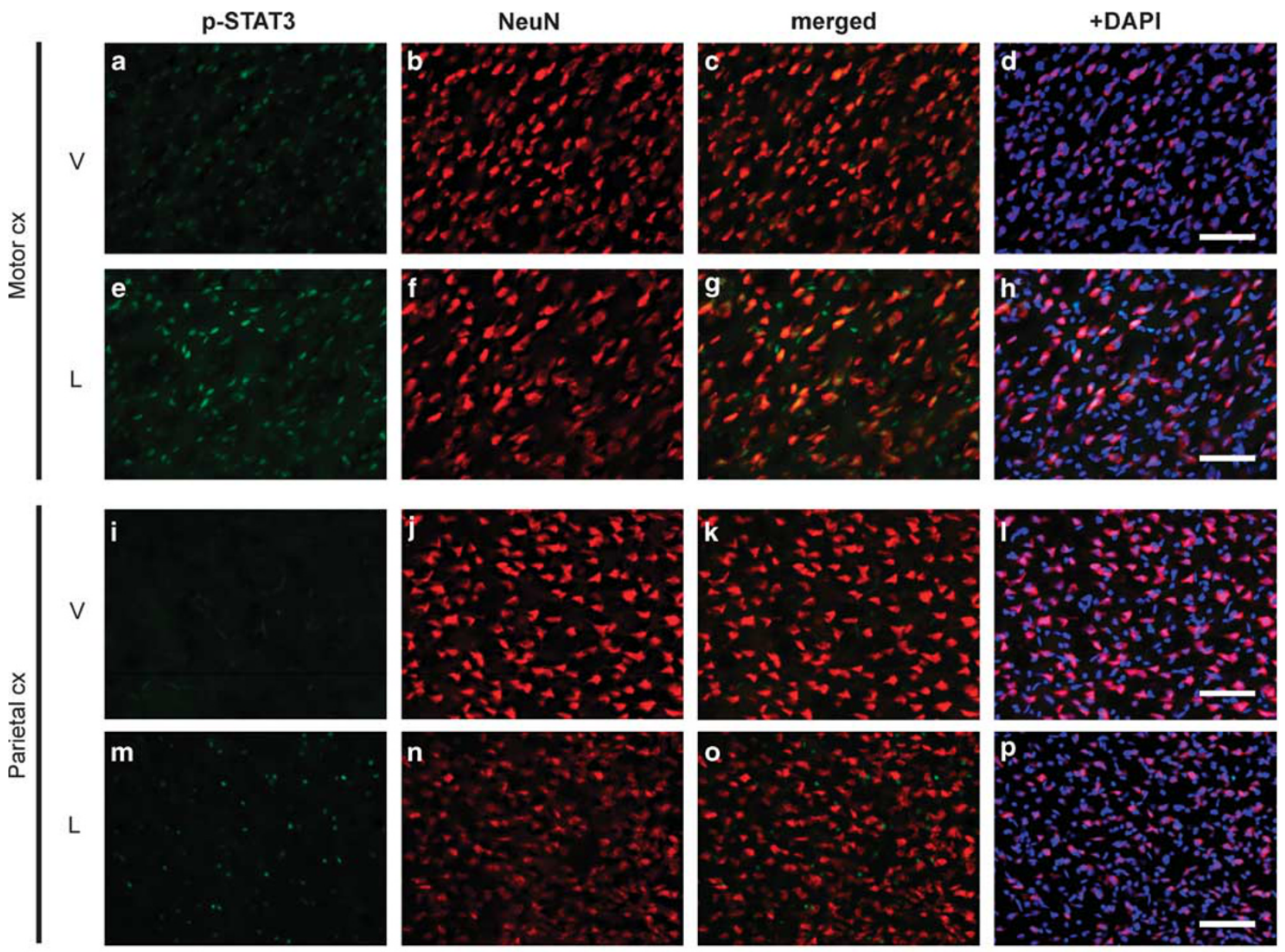

p-STAT3
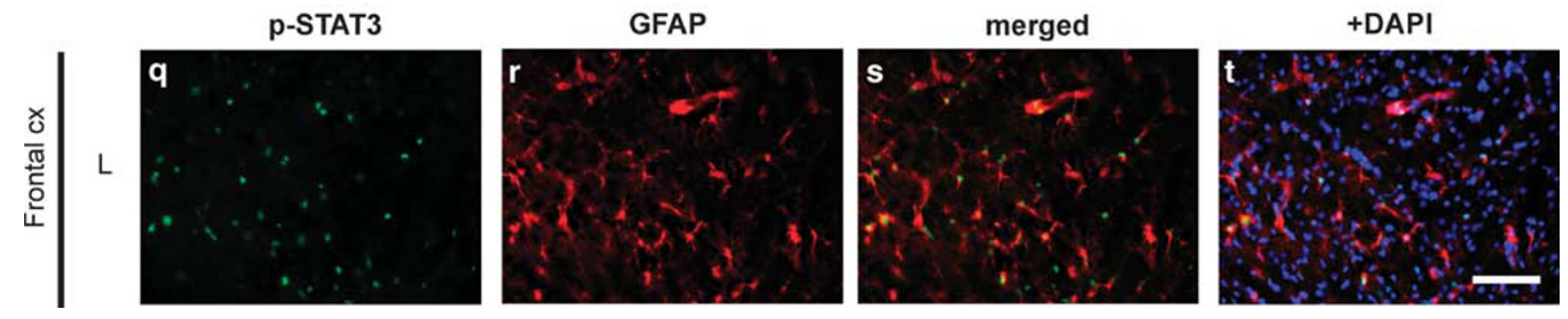

Figure 6 Double p-STAT3/NeuN (a-p) and p-STAT3/GFAP ( $\mathbf{q}-\mathbf{t})$ immunoreactivity in the ipsilateral motor $(\mathbf{a}-\mathbf{h})$, parietal (i-p) and frontal (q- $\mathbf{t})$ cortices of rats subjected to $24 \mathrm{~h}$ permanent MCAo. Leptin (L, $1 \mathrm{mg} / \mathrm{kg}$, s.c.) or vehicle (V, PBS, $1 \mathrm{ml} / \mathrm{kg})$ were administered $3 \mathrm{~h}$ before the induction of ischemia. Nuclei were counterstained with 4',6-diamidino-2-phenylindole (DAPI). Scale bars $=100 \mu \mathrm{m}$ 

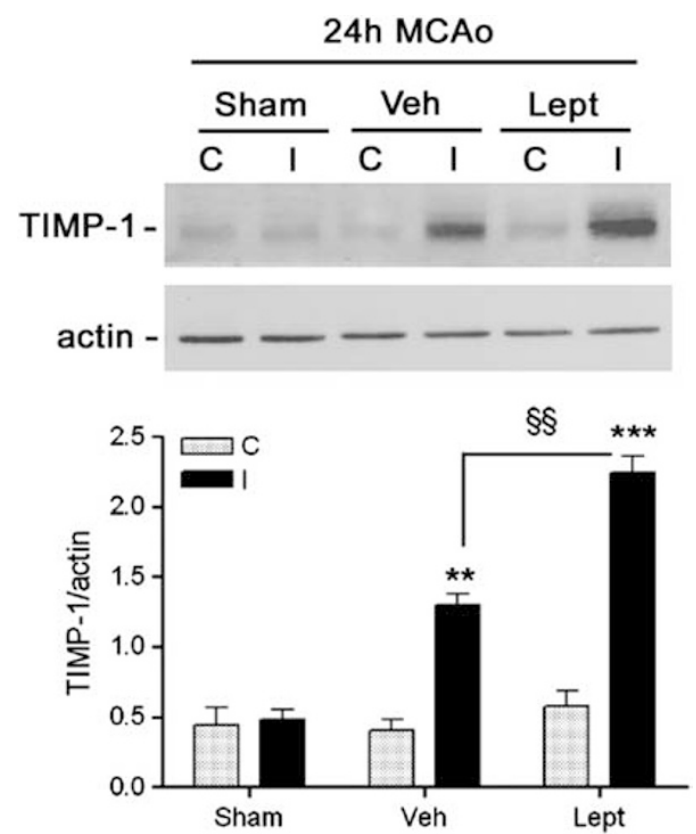

Figure 7 Changes in TIMP-1 expression following focal brain ischemia as determined by western blot analysis performed on brain cortical homogenates from the ipsilateral (I) and contralateral (C) cortex of rats treated with vehicle (Veh) or leptin (Lept) and killed $24 \mathrm{~h}$ after MCAo. The results are representative of three independent experiments. Histograms show the results of the densitometric analysis of the autoradiographic bands; ${ }^{\star \star} P<0.01$ and ${ }^{\star * \star} P<0.001$ versus contralateral $(C)$ side. ${ }^{\S \S} P<0.01$ (Leptin versus Vehicle)

Tissue inhibitor of matrix metalloproteinases-1 (TIMP-1) is one of STAT3's target genes, which has been shown to be induced by leptin in vitro. TIMP-1 expression is barely detectable in the cortical brain tissue from rats subjected to $3 \mathrm{~h} \mathrm{MCAo}$ or sham operation (data not shown); however, expression of TIMP-1 significantly enhances in the ipsilateral cortex $24 \mathrm{~h}$ after permanent MCAo (Figure 7). As shown in Figure 7, leptin almost doubled cortical TIMP-1 expression induced by MCAo in the rat.

\section{Discussion}

Our data demonstrate that systemic, acute, pretreatment with leptin reduces the brain infarct damage and neurological deficit produced by permanent focal cerebral ischemia in the rat. Neuroprotection is long lasting and seems to occur via modulation of STAT3 phosphorylation. In fact, the early enhancement of nuclear p-STAT3 induced by leptin in the astrocytes of the ischemic penumbra may contribute to a beneficial effect of these cells on the evolution of tissue damage. In addition, the elevation of p-STAT3 induced by leptin in the neurons after $24 \mathrm{~h} \mathrm{MCAo}$ is associated with an increased expression of TIMP-1 in the cortex, suggesting its possible involvement to the neuroprotection exerted by the adipokine.

Previous findings have demonstrated neuroprotection by leptin against ischemic brain injury. In fact, the adipokine protects rat primary cortical neurons against death induced by oxygen-glucose deprivation (OGD) via the ERK 1/2 signaling pathway, ${ }^{5}$ and mouse cortical neurons exposed to OGD via the induction of the expression of the anti-apoptotic c-Rel target gene $B C l-x L .{ }^{10}$ In vivo, neuroprotection by leptin was observed in different ischemic models, including global and focal cerebral ischemia. Exogenous administration of this adipokine provides neuroprotection in mice subjected to transient ${ }^{5}$ or permanent ${ }^{10}$ occlusion of the middle cerebral artery, whereas little information is available in the rat.

Our findings represent the first evidence of neuroprotection by leptin in a rat model of permanent MCAo and are consistent with previous observations documenting neuroprotection by leptin under similar experimental conditions in mice. ${ }^{10}$ Moreover, we have extended these previous findings by demonstrating that the neuroprotection provided by an acute treatment with leptin is long lasting as it produces a significant reduction of the infarct volume and neurological deficit up to 7 days after the induction of ischemia in the rat.

According to Zhang et al., ${ }^{5}$ we did not find significant changes in the CBF after leptin treatment, excluding the possibility that hemodynamic modifications mediate the neuroprotective effect of this adipokine. Although acute administration of pharmacological doses of leptin $(10-1000 \mathrm{~m} / \mathrm{kg})$ increases the plasma concentration of nitric oxide metabolites and of its second messenger, cGMP, ${ }^{11}$ studies performed in conscious animals suggest that leptin-induced endothelial nitric oxide has little, if any, hemodynamic role. ${ }^{12}$

We failed to observe any protective effect of leptin when it was administered at onset of MCAo. The lack of protection under a similar treatment schedule was also reported in mice subjected to transient MCAo. ${ }^{13}$ By contrast, Zhang et al. ${ }^{5}$ observed neuroprotection following treatment with leptin up to $90 \mathrm{~min}$ after the beginning of reperfusion in mice. The apparent discrepancy between this latter evidence and our data may stem from the different experimental model and animal species used, the permanent MCAo in the rat being insensitive to leptin post-treatment.

Clinical studies suggest that elevated circulating leptin levels, such as those frequently found in obesity, are independently associated with elevated cardiovascular risk. Accordingly, large population-based studies suggest a strong positive association between increased plasma leptin levels and stroke. ${ }^{14-16}$ Indeed, experimental studies have shown that leptin exerts prothrombotic effects in vivo. ${ }^{17}$

In addition to clinical data that have indicated increased risk of stroke in obese individuals, ${ }^{18}$ recent studies have shown that the severity of brain damage is increased after experimental stroke in obese rodents ${ }^{19}$ and this effect appears to be independent of leptin deficiency. In fact, the increased incidence of hemorrhagic transformation and the exacerbation of inflammatory responses and ischemic brain damage observed in obese ob/ob mice were not affected by systemic treatment with leptin. ${ }^{13,19}$ As obesity may be a consequence of leptin resistance, the latter likely resulting from an impaired transport of this hormone across the blood brain barrier, ${ }^{20}$ it is intriguing to speculate that the reduced access of leptin to the brain may be responsible for the increased susceptibility of obese subjects to the ischemic insult. Moreover, Valerio et $a l .{ }^{10}$ have shown that leptin mRNA levels and protein expression increase in the microglia/macrophages populating the perilesional cerebral cortex of mice subjected to permanent MCAo. Indeed, this may represent an endogenous 
(repair) mechanism activated either peripherally or locally to rescue the damaged tissue, although further studies are needed to clarify this hypothesis.

In order to evaluate the molecular mechanisms involved in neuroprotection, previous studies have primarily focused on the effects of leptin on injured neurons, arguing that an increase of pERK expression ${ }^{5}$ or the induction of c-Reldependent target genes ${ }^{10}$ in these cells underlie the beneficial effects of the hormone against an ischemic insult.

Surprisingly, although being a major mediator of ObR transduction pathway in the brain, ${ }^{9}$ STAT3 and its contribution to leptin neuroprotection under ischemic conditions was only marginally studied. Levels of p-STAT3 measured by western blotting in whole tissue homogenates from brain of ischemic rodents were only slightly affected by leptin treatment, ${ }^{5}$ probably because of the different cellular (glia versus neurons) source and subcellular compartmentalization of this mediator. This represents a major limitation of previous studies, as activation of STAT proteins implicates their phosphorylation and nuclear translocation to induce gene transcription. By using a cell fractionation approach, combined with immunofluorescence, here we have demonstrated that cell-specific STAT3 activation may represent a pivotal mechanism recruited by leptin to afford neuroprotection.

Our data demonstrate that p-STAT3 is significantly elevated in the ipsilateral brain hemisphere after permanent MCAo, being its nuclear translocation increased with the progression of the insult. Neuroprotection by leptin is associated with a further elevation of p-STAT3 in the nuclear (at $3 \mathrm{~h} \mathrm{MCAo}$ ) and cytosolic (at $24 \mathrm{~h} \mathrm{MCAo}$ ) fractions of the ischemic cortex. An increased phosphorylation of STAT3 on Tyr-705 was reported after either permanent or transient focal cerebral ischemia. ${ }^{21,22}$ Despite some studies have suggested that phosphorylation of STAT3 might be involved in neuronal death after cerebral ischemia, ${ }^{22,23}$ our data are consistent with other findings claiming a protective role. ${ }^{21,24,25}$ Indeed, STAT3 induces the expression of neuroprotective genes, such as $b c l-2, b c l-x L^{26-28}$ and TIMP-1. ${ }^{29}$ Accordingly, we have observed that the increased levels of $p$-STAT3 produced by leptin in the ischemic cortex are associated with the elevation of TIMP-1 expression, suggesting that this latter mediator may underlie the beneficial effects of the adipokine.

More interestingly, we have observed that neuroprotection by leptin is associated with elevation of p-STAT3 in the nuclei of the astrocytes of the cortical penumbra, as early as $3 \mathrm{~h}$ after permanent MCAo. Previous findings have demonstrated that leptin is induced in the brain microglia/macrophages after stroke ${ }^{10}$ and glial cells, in turn, express both the long and short form of the leptin receptor. ${ }^{6}$ Astrocytes-expressing ObR may have a role in the regulation of food intake, ${ }^{7}$ and recent findings have also suggested that the modulation of astrocytic activity by leptin is implicated in hypothalamic synaptic rearrangement. ${ }^{30}$

STAT3 is required for complete differentiation of astrocytes and regulates the expression of GFAP, a hallmark indicator of astrogliosis, via a STAT-responsive element in the GFAP promoter. $^{31,32}$ The crucial role of STAT3 in the regulation of astroglial reaction in vivo has been demonstrated in several experimental models of brain injury, such as following excitotoxic brain lesions, kainic acid-induced seizures and, most notably, transient cerebral ischemia. ${ }^{33}$ The protective role of reactive astrocytes in stroke is well documented; moreover, astrocytes have been suggested to promote neuronal survival and differentiation. ${ }^{34}$ Under ischemic conditions, activation of STAT3 signaling pathway in astrocytes underlies the neuroprotective effects of cytokines acting on gp130 receptor, a molecule belonging to the same (interleukin-6-type cytokine) receptor family as ObR. ${ }^{8}$

In line with these previous findings, our data suggest that STAT3 activation might contribute to astrocytic activation under ischemic conditions and, more importantly, the neuroprotective effect of leptin is due to an early regulation of reactive astrocytes, via increased STAT3 phosphorylation. Induction of reactive astrogliosis may thus represent a pivotal mechanism activated by leptin early after permanent MCAo to rescue the peripheral territories of the penumbra.

By contrast, $24 \mathrm{~h}$ after MCAo we observe that elevation of p-STAT3 does mainly occur in the neurons of the peri-infarct cortex and in glial cells throughout the ischemic hemisphere. This is consistent with previous findings obtained under conditions of transient MCAo. ${ }^{21,25,35}$ More interestingly, we observe that neuroprotection by leptin is associated with increased levels of p-STAT3 in the neurons of the cortical penumbra. Thus, in addition to the early recruitment of a beneficial astrocytic response, leptin may act directly on the neurons to promote their survival, probably via elevation of downstream TIMP-1 expression. Our data are consistent with the knowledge that STAT3 activation has a beneficial role in neurons under a variety of brain pathological conditions, ${ }^{35}$ including transient focal cerebral ischemia. ${ }^{24,25}$ By contrast, excessive STAT3 activation in microglia-macrophages has been demonstrated to provide a detrimental effect after ischemia-reperfusion injury, ${ }^{23}$ further suggesting that a differential cellular activation of this mediator may serve different functions.

According to previous findings, ${ }^{36,37}$ we have found a transient enhancement of $p$-Akt in the ischemic cortex of rats subjected to pMCAo. Activation of the PI3K/Akt pathway has been suggested to specifically occur in the neurons of the ischemic penumbra and is believed to rescue these cells from delayed cell death. ${ }^{36}$ Notably, the PI3K/Akt pathway is implicated in leptin signaling in neurons and there is evidence suggesting a role of JAK2/STAT3 upstream of PI3K/Akt upon leptin exposure in neurons. Here, we observe that leptin only transiently modifies p-Akt levels in the ischemic cortex, having no effect on the time-course activation of this signaling pathway during permanent MCAo. Thus, although we cannot exclude that this pathway may contribute to the neuroprotection provided by leptin after stroke injury, the effect on STAT3 activation/phosphorylation appears to have a more specific and significant role.

In conclusion, our findings demonstrate that the neuroprotection exerted by leptin in a rat model of permanent focal cerebral ischemia is associated with modulation of STAT3 phosphorylation in different cellular populations of the injured brain. In particular, by increasing nuclear translocation of p-STAT3, leptin may promote a beneficial astrocytic reaction in the ischemic penumbra triggered as early as few hours after the insult. By contrast, at later stages, the adipokine elevates p-STAT3 in neurons and this is coincident with the induction of 
the neuroprotective protein TIMP-1. These differential mechanisms are associated with a long-lasting neuroprotection after an acute treatment with leptin, being both the infarct volume and the neurological deficit produced by permanent MCAo significantly reduced up to 7 days after the insult. Together with the already established safety of leptin treatment in human, ${ }^{38}$ these data underscore the therapeutic potential of this adipokine for the treatment of ischemic brain injury.

\section{Methods}

Focal cerebral ischemia and drug treatments. Adult male Wistar rats (Charles River, Calco, Como, Italy) were housed under controlled environmental conditions with ambient temperature of $22{ }^{\circ} \mathrm{C}$, relative humidity of $65 \%$ and $12 \mathrm{~h}$ light: $12 \mathrm{~h}$ dark cycle, with free access to food and water.

Brain ischemia was induced by occlusion of the middle cerebral artery in rats weighing $280-320 \mathrm{~g}$ by intraluminal filament, using a relatively non-invasive technique as described previously. ${ }^{39,40}$ Briefly, rats were anaesthetized with $5 \%$ isoflurane in air, and were maintained with the lowest acceptable concentration of the anesthetic $(1.5-2 \%)$. Body temperature was measured with a rectal probe and was maintained at $37^{\circ} \mathrm{C}$ during the surgical procedure with a heating pad. Under an operating microscope, the external and internal right carotid arteries were exposed through a neck incision. The external carotid artery was cut $\sim 3 \mathrm{~mm}$ above the common carotid artery bifurcation and a silk suture was tied loosely around the external carotid stump. A silicone-coated nylon filament (diameter: $0.37 \mathrm{~mm}$, Doccol Corporation, Redlands, CA, USA) was then inserted into the external carotid artery and gently advanced into the internal carotid artery, $\sim 18 \mathrm{~mm}$ from the carotid bifurcation, until mild resistance was felt, thereby, indicating occlusion of the origin of the middle cerebral artery in the Willis circle. The silk suture was tightened around the intraluminal filament to prevent bleeding. The wound was then sutured and anesthesia discontinued.

During surgery, CBF was monitored over the cerebral cortex of the ischemic hemisphere, corresponding to the supply territory of the middle cerebral artery, by lased-Doppler flowmetry (Periflux System 5000, Perimed, Stockholm, Sweden). To this aim, a flexible laser-Doppler probe was glued onto the parietal bone $(2 \mathrm{~mm}$ posterior and $6 \mathrm{~mm}$ lateral from bregma) and local CBF was continuously measured from 15 min before the onset of ischemia until $10 \mathrm{~min}$ after MCAo, keeping the animal under isoflurane anesthesia. Changes in regional CBF during ischemia were calculated as a percentage of the preischemic basal values.

Sham rats were exposed to the same surgical procedure without occlusion of MCA.

Recombinant rat leptin (ProSpec-Tany TechnoGene Ltd., Rehovot, Israel; $1 \mathrm{mg} / \mathrm{kg}$ ) or vehicle (PBS, $1 \mathrm{ml} / \mathrm{kg}$ ) were administered s.c. $6 \mathrm{~h}, 3 \mathrm{~h}$ or immediately before MCAO. To assess the effect of leptin on body weigh, rats were weighed immediately before surgery and, then, daily before killing.

All the experimental procedures were carried out in accordance with the European Community Council Directive of 24 November 1986 (86/609/EEC), included in the DM 116/1992 of the Italian Ministry of Health.

Neuropathology and quantification of ischemic damage. After $24 \mathrm{~h}$ permanent MCAo, the cerebral infarct volume was evaluated by the 2,3 , 5 -triphenyltetrazolium chloride (TTC) staining technique. Briefly, rats were killed by decapitation and the brains were rapidly removed from the skull. Eight serial sections from each brain were cut at 2-mm intervals from the frontal pole using a rat brain matrix (Harvard Apparatus, Holliston, MA, USA). To measure ischemic damage, brain slices were stained in a solution containing $2 \%$ TTC in saline, at $37^{\circ} \mathrm{C}$. After $10 \mathrm{~min}$ incubation, the slices were transferred to $10 \%$ neutral buffered formaldehyde and stored at $4{ }^{\circ} \mathrm{C}$ before analysis.

To evaluate infarct volume 3 or 7 days after MCAo, brains were removed from the skull and immediately frozen in isopentane cooled with dry ice. Eight $20 \mu \mathrm{m}$-thick coronal sections were cut, at $2 \mathrm{~mm}$ intervals from the frontal pole, using a cryostat, and stained with cresyl violet.

Images of TTC- or cresyl violet-stained sections were captured by a digital scanner and analyzed using an image analysis software (ImageJ, version 1.30, US National Institutes of Health, Bethesda, MD, USA). Infarct volume $\left(\mathrm{mm}^{3}\right)$ was determined by summing the infracted (pale) areas of the eight coronal tissue slices and multiplying the obtained value by the interval thickness between sections $(2 \mathrm{~mm})$.

Neurological examination. Neurological deficits in rats were examined daily, up to 7 days after permanent MCAo, by an investigator (FP) blinded to the treatment. The deficits were scored on a modified scoring system based on that developed by Longa et al., ${ }^{39}$ as follows: 0 , no deficit; 1 , failure to fully extend the contralateral forelimb; 2 , reduced resistance to a lateral push; 3 , circling to contralateral side; 4 , falling to contralateral side; 5 , no spontaneous walking with depressed level of consciousness.

Preparation of brain tissue homogenates. Individual cortical tissue samples of sham-operated rats and of rats subjected to permanent focal cerebral ischemia ( $n=3$ per group) were rapidly dissected out and homogenized in a glass homogenizer using six volumes of ice-cold lysis buffer containing $50 \mathrm{mM}$ Tris- $\mathrm{HCl}$, $\mathrm{pH} 7.5,150 \mathrm{mM} \mathrm{NaCl}, 2 \mathrm{mM}$ EDTA, $2 \mathrm{mM}$ EGTA, 1\% Triton, $1 \mathrm{nM}$ okadaic acid, a cocktail of protease inhibitors (code P8340, Sigma, Milan, Italy) and a cocktail of phosphatase inhibitors (code 524625, Calbiochem, La Jolla, CA, USA); samples were then centrifuged at $10000 \times g$ for $15 \mathrm{~min}$ at $4^{\circ} \mathrm{C}$. Protein concentration in the supernatant was determined by the DC protein assay (Bio-Rad Laboratories, Milan, Italy).

Subcellular fractionation. The cytosolic and nuclear protein extracts were prepared from rat brain cortices dissected 3 and $24 \mathrm{~h}$ after ischemia or sham operation ( $n=3$ per group). The tissues were first homogenized in an ice-cold hypotonic buffer containing $320 \mathrm{mM}$ sucrose, $10 \mathrm{mM}$ Tris- $\mathrm{HCl}$, pH 7.4, $1 \mathrm{nM}$ okadaic acid, a cocktail of protease inhibitors (code P8340, Sigma) and a cocktail of phosphatase inhibitors (code 524625, Calbiochem) and the homogenates were centrifuged twice at 1300 for $5 \mathrm{~min}$ to pellet nuclei. The supernatants were centrifuged at $17000 \times g$ for $10 \mathrm{~min}$ to pellet the mitochondria; the postmitochondrial supernatants were centrifuged at $100000 \times g$ for $1 \mathrm{~h}$ and the highspeed supernatant retained as a cytosolic fraction. The crude nuclear pellets were resuspended in $0.35 \mathrm{ml}$ of sucrose buffer, subjected to three freeze-thaw cycles and then sonified for $30 \mathrm{~s}$ on ice; the nuclear suspensions were then centrifuged at $40000 \times g$ for $30 \mathrm{~min}$ to remove insoluble material. Protein concentration was determined by using the Bio-Rad DC protein assay (Bio-Rad Laboratories). All procedures were performed at $4{ }^{\circ} \mathrm{C}$.

Western blot analysis. Proteins were resolved by sodium dodecyl sulfatepolyacrylamide gel electrophoresis and electrotransferred to nitrocellulose membranes (Optitran BA-S 83, Schleicher \& Schuell Bioscence, Dassel, Germany). Primary antibodies were incubated overnight at $4{ }^{\circ} \mathrm{C}$ followed by a horseradish peroxidase-conjugated secondary antibody for $1 \mathrm{~h}$ at room temperature. Immunoreactivity was visualized by enhanced chemiluminescent detection (Amersham Biosciences, GE Healthcare, Milan, Italy) and exposure to X-ray films (Hyperfilm ECL, Amersham Biosciences). Autoradiographic films were scanned and densitometric analysis was carried out using Quantiscan software (Biosoft, Cambridge, UK). The following primary antibodies were used: a rabbit polyclonal antibody for P-STAT3 (Tyr705) at 1:1000 dilution (code 9131, Cell Signaling Technology, Beverly, MA, USA), a rabbit polyclonal antibody for STAT3 at 1:1000 dilution (code 9132, Cell Signaling Technology), a rabbit polyclonal antibody for p-Akt at 1:1000 dilution (code 9271, Cell Signaling Technology), a rabbit polyclonal antibody for Akt at 1:2000 dilution (code 9272, Cell Signaling Technology), a mouse monoclonal antibody for TIMP-1 at 1:200 dilution (code MAB13428, Chemicon International Inc., Temecula, CA, USA), a mouse monoclonal anti-actin antibody at 1:2000 dilution (clone AC-40; Sigma).

Immunohistochemistry. After 3 and $24 \mathrm{~h}$ of $\mathrm{MCAO}$, animals were anesthetized with sodium pentobarbital $(60 \mathrm{mg} / \mathrm{kg}$, intraperitoneal) and perfused through the heart with saline $(0.9 \% \mathrm{NaCl})$ followed by $4 \%$ paraformaldehyde in phosphate buffer (PB; $0,1 \mathrm{M}$; pH 7.4), containing $50 \mathrm{mM} \mathrm{NaF}$. Each brain was rapidly removed, post-fixed in the same fixative for $2 \mathrm{~h}$ and, after three washes in $\mathrm{PB}$, transferred to $30 \%$ sucrose in PB solution at $4{ }^{\circ} \mathrm{C}$ until it sank. A volume of $40 \mu \mathrm{m}$-thick coronal brain sections, at the level of the MCA territory $(1.7$ to $-3.3 \mathrm{~mm}$ from Bregma), were obtained using a freezing microtome and collected in PB.

For p-STAT immunostaining, tissue slices were pre-treated with $1 \% \mathrm{NaOH}$ and $1 \% \mathrm{H}_{2} \mathrm{O}_{2}$ in $\mathrm{H}_{2} \mathrm{O}$ for $20 \mathrm{~min}, 0.3 \%$ glycine (in $\mathrm{PB}$ ) for $10 \mathrm{~min}$, and $0.03 \%$ sodium dodecyl sulfate (in PB) for 10 min. After two washes in $\mathrm{PB}$, the sections were pre-incubated for $1 \mathrm{~h}$ in blocking solution (3\% normal donkey serum, $0.2 \%$ Triton 
$\mathrm{X}-100,0.2 \%$ sodium azide in $\mathrm{PB}$ ), and then the primary antibodies were added and incubated for $24 \mathrm{~h}$ at $4{ }^{\circ} \mathrm{C}$. Colocalization studies were performed as described previously, ${ }^{40}$ using a combination of the following primary antibodies: rabbit polyclonal anti-p-STAT3 (1:200 dilution; Tyr705, Cell Signaling Technology), mouse anti-GFAP (anti-GFAP; 1:200 dilution; code AB5804, Merck Millipore, Milan, Italy) to label astrocytes, or mouse anti-NeuN (anti-neuronal nuclei; 1:200 dilution; MAB377, Chemicon International) to label neurons.

Thereafter, sections were incubated for $2 \mathrm{~h}$ at room temperature in a solution containing an appropriate mixture of the corresponding secondary antibodies: Alexa Fluor 488 donkey anti-rabbit and Alexa Fluor 594 donkey anti-mouse IgG (1:400 dilution; Molecular Probes; Invitrogen, Milan, Italy). Finally, nuclei were counterstained with 4',6-diamidino-2-phenylindole (1:500; Sigma-Aldrich, Milan, Italy), and the sections were mounted on gelatin-coated slides, air-dried and coverslipped with Fluoromount (Diagnostic BioSystems, Pleasanton, CA, USA).

To rule out interference of non-specific staining, control experiments were performed under conditions identical to those described above, with the omission of primary antibody.

Immunostaining was examined under a fluorescence microscope (Leica DMI6000B, Leica Microsystems Srl, Milan, Italy) equipped with a high-resolution digital camera (Leica DFC350FX) and a dedicated software (LAS AF6000) for image analysis and deconvolution.

\section{Conflict of interest}

The authors declare no conflict of interest.

Acknowledgements. Partial financial support from the Italian Ministry of Health (RF05.105 to MTC and Ricerca Corrente 2009 to CT) and from the Italian Ministry of University and Research (PRIN prot. 20089BARSR_004 to GB) is gratefully acknowledged.

1. Harvey J. Leptin: a diverse regulator of neuronal function. $J$ Neurochem $2007 ; 100$ 307-313.

2. Bouret SG. Neurodevelopmental actions of leptin. Brain Res 2010; 1350: 2-9.

3. Tang BL. Leptin as a neuroprotective agent. Biochem Biophys Res Comm 2008; 368 : 181-185.

4. Elmquist JK, Bjørbaek C, Ahima RS, Flier JS, Saper CB. Distributions of leptin receptor mRNA isoforms in the rat brain. J Comp Neurol 1998; 395: 535-547.

5. Zhang F, Wang S, Signore AP, Chen J. Neuroprotective effects of leptin against ischemic injury induced by oxygen-glucose deprivation and transient cerebral ischemia. Stroke 2007; 38: 2329-2336.

6. Hosoi T, Okuma Y, Nomura Y. Expression of leptin receptors and induction of IL-1beta transcript in glial cells. Biochem Biophys Res Commun 2000; 273: 312-315

7. Cheunsuang $\mathrm{O}$, Morris R. Astrocytes in the arcuate nucleus and median eminence that take up a fluorescent dye from the circulation express leptin receptors and neuropeptide $Y$ Y1 receptors. Glia 2005; 52: 228-233

8. Baumann H, Morella KK, White DW, Dembski M, Bailon PS, Kim H et al. The full-length leptin receptor has signaling capabilities of interleukin 6-type cytokine receptors. Proc Natl Acad Sci USA 1996; 93: 8374-8378.

9. Vaisse C, Halaas JL, Horvath CM, Darnell Jr JE, Stoffel M, Friedman JM. Leptin activation of Stat3 in the hypothalamus of wild-type and ob/ob mice but not db/db mice. Nat Genet 1996; 14: 95-97.

10. Valerio A, Dossena M, Bertolotti P, Boroni F, Sarnico I, Faraco G et al. Leptin is induced in the ischemic cerebral cortex and exerts neuroprotection through NFkappaB/c-Reldependent transcription. Stroke 2009; 40: 610-617.

11. Beltowski J, Wojcicka G, Borkowska E. Human leptin stimulates systemic nitric oxide production in the rat. Obes Res 2002; 10: 939-946.

12. Mitchell JL, Morgan DA, Correia ML, Mark AL, Sivitz WI, Haynes WG. Does leptin stimulate nitric oxide to oppose the effects of sympathetic activation? Hypertension 2001; 38: 1081-1086.

13. McColl BW, Rose N, Robson FH, Rothwell NJ, Lawrence $\mathrm{CB}$. Increased brain microvascular MMP-9 and incidence of haemorrhagic transformation in obese mice after experimental stroke. J Cereb Blood Flow Metab 2010; 30: 267-272.

14. Söderberg S, Stegmayr B, Stenlund H, Sjöström LG, Agren A, Johansson L et al. Leptin, but not adiponectin, predicts stroke in males. J Intern Med 2004; 256: 128-136.

15. Sierra-Johnson J, Romero-Corral A, Lopez-Jimenez F, Gami AS, Sert Kuniyoshi FH, Wolk $\mathrm{R}$ et al. Relation of increased leptin concentrations to history of myocardial infarction and stroke in the United States population. Am J Cardiol 2007; 100: 234-239.

16. Liu J, Butler KR, Buxbaum SG, Sung JH, Campbell BW, Taylor HA. Leptinemia and its association with stroke and coronary heart disease in the Jackson Heart Study. Clin Endocrinol (Oxf) 2010; 72 : 32-37.
17. Konstantinides S, Schäfer K, Loskutoff DJ. The prothrombotic effects of leptin possible implications for the risk of cardiovascular disease in obesity. Ann NY Acad Sci 2001; 947: 134-141.

18. Winter $\mathrm{Y}$, Rohrmann S, Linseisen J, Lanczik O, Ringleb PA, Hebebrand $\mathrm{J}$ et al. Contribution of obesity and abdominal fat mass to risk of stroke and transient ischemic attacks. Stroke 2008; 39: 3145-3151.

19. Terao S, Yilmaz G, Stokes KY, Ishikawa M, Kawase T, Granger DN. Inflammatory and injury responses to ischemic stroke in obese mice. Stroke 2008; 39: 943-950.

20. Banks WA. The blood-brain barrier as a cause of obesity. Curr Pharm Des 2008; 14 1606-1614.

21. Suzuki S, Tanaka K, Nogawa S, Dembo T, Kosakai A, Fukuuchi Y. Phosphorylation of signal transducer and activator of transcription-3 (Stat3) after focal cerebral ischemia in rats. Exp Neurol 2001; 170: 63-71.

22. Wen TC, Peng H, Hata R, Desaki J, Sakanaka M. Induction of phosphorylated-STAT3 following focal cerebral ischemia in mice. Neurosci Lett 2001; 303: 153-156.

23. Satriotomo I, Bowen KK, Vemuganti R. JAK2 and STAT3 activation contributes to neuronal damage following transient focal cerebral ischemia. J Neurochem 2006; 98 1353-1368.

24. Yamashita T, Sawamoto K, Suzuki S, Suzuki N, Adachi K, Kawase T et al. Blockade of interleukin-6 signaling aggravates ischemic cerebral damage in mice: possible involvement of Stat3 activation in the protection of neurons. J Neurochem 2005; 94 $459-468$.

25. Komine-Kobayashi M, Zhang N, Liu M, Tanaka R, Hara H, Osaka A et al. Neuroprotective effect of recombinant human granulocyte colony-stimulating factor in transient focal schemia of mice. J Cereb Blood Flow Metab 2006; 26: 402-413.

26. Stephanou A, Brar BK, Knight RA, Latchman DS. Opposing actions of STAT-1 and STAT-3 on the Bcl-2 and Bcl-x promoters. Cell Death Differ 2000; 7: 329-330.

27. Jourdan M, De Vos J, Mechti N, Klein B. Regulation of Bcl-2-family proteins in myeloma cells by three myeloma survival factors: interleukin-6, interferon-alpha and insulin-like growth factor 1. Cell Death Differ 2000; 7: 1244-1252.

28. Sepulveda $\mathrm{P}$, Encabo A, Carbonell-Uberos $\mathrm{F}$, Miñana MD. BCL-2 expression is mainly regulated by JAK/STAT3 pathway in human CD34+ hematopoietic cells. Cell Death Diff 2007; 14: 378-391.

29. Lin S, Saxena NK, Ding X, Stein LL, Anania FA. Leptin increases tissue inhibitor of metalloproteinase I (TIMP-1) gene expression by a specificity protein 1/signal transduce and activator of transcription 3 mechanism. Mol Endocrinol 2006; 20: 3376-3388.

30. García-Cáceres C, Fuente-Martín E, Burgos-Ramos E, Granado M, Frago LM, Barrios V et al. Differential acute and chronic effects of leptin on hypothalamic astrocyte morphology and synaptic protein levels. Endocrinology 2011; 152: 1809-1818.

31. Takizawa T, Yanagisawa M, Ochiai W, Yasukawa K, Ishiguro T, Nakashima K et al. Directly linked soluble IL-6 receptor-IL-6 fusion protein induces astrocyte differentiation from neuroepithelial cells via activation of STAT3. Cytokine 2001; 13: 272-279.

32. Fukuda $\mathrm{S}$, Kondo $\mathrm{T}$, Takebayashi $\mathrm{H}$, Taga $\mathrm{T}$. Negative regulatory effect of an oligodendrocytic bHLH factor OLIG2 on the astrocytic differentiation pathway. Cell Death Diff 2004; 11: 196-202.

33. Justicia C, Gabriel C, Planas AM. Activation of the JAK/STAT pathway following transient focal cerebral ischemia: signaling through Jak1 and Stat3 in astrocytes. Glia 2000; 30: 253-270.

34. Cordero-Llana O, Scott SA, Maslen SL, Anderson JM, Boyle J, Chowhdury RR et al. Clusterin secreted by astrocytes enhances neuronal differentiation from human neural precursor cells. Cell Death Differ 2011; 18: 907-913.

35. Dziennis S, Alkayed NJ. Role of signal transducer and activator of transcription 3 in neuronal survival and regeneration. Rev Neurosci 2008; 19: 341-361.

36. Zhao H, Sapolsky RM, Steinberg GK. Phosphoinositide-3-kinase/Akt surviva signal pathways are implicated in neuronal survival after stroke. Mol Neurobiol 2006; 34: 249-269.

37. Amantea D, Fratto V, Maida S, Rotiroti D, Ragusa S, Nappi G et al. Prevention of glutammate accumulation and upregulation of phospho-Akt may account for neuroprotection afforded by bergamot essential oil against brain injury induced by focal cerebral ischemia in rat. Int Rev Neurobiol 2009; 85: 389-405.

38. Heymsfield SB, Greenberg AS, Fujioka K, Dixon RM, Kushner R, Hunt T et al. Recombinant leptin for weight loss in obese and lean adults: a randomized, controlled dose-escalation trial. JAMA 1999; 282: 1568-1575.

39. Longa EZ, Weinstein PR, Carlson S, Cummins R. Reversible middle cerebral artery occlusion without craniotomy in rats. Stroke 1989; 20: 84-91.

40. Amantea D, Bagetta G, Tassorelli C, Mercuri NB, Corasaniti MT. Identification of distinct cellular pools of interleukin- $1 \beta$ during the evolution of the neuroinflammatory response induced by transient middle cerebral artery occlusion in the brain of rat. Brain Res 2010 1313: 259-269.

Cell Death and Disease is an open-access journal published by Nature Publishing Group. This work is licensed under the Creative Commons Attribution-Noncommercial-No Derivative Works 3.0 Unported License. To view a copy of this license, visit http://creativecommons.org/licenses/by-nc-nd/3.0/ 